\title{
Responses to reciprocal recurrent selection and changes in genetic variability in IG-1 and IG-2 maize populations
}

\author{
Mateus Figueiredo Santos, Gustavo Vitti Moro, Aurélio Mendes Aguiar and Cláudio Lopes de Souza Jr. \\ Universidade de São Paulo, Escola Superior de Agricultura "Luiz de Queiroz", \\ Departamento de Genética, Piracicaba, SP, Brazil.
}

\begin{abstract}
This paper reports the effects of three cycles of reciprocal recurrent selection (RRS) on the means, genetic variances, and on the genetic correlations for several traits in the IG-1 and IG-2 maize (Zea mays L.) populations. Interpopulation full-sib progenies from cycle zero $\left(\mathrm{C}_{0}\right)$ and from cycle $3\left(\mathrm{C}_{3}\right)$ of RRS were evaluated in two locations. RRS was highly effective to improve the traits according the objectives of the program: grain yield and prolificacy increased significantly, while plant height, ear height, and ear placement decreased significantly. Genetic variances for all traits decreased significantly from $\mathrm{C}_{0}$ to $\mathrm{C}_{3}$, but the genetic correlations did not change consistently across the cycles of selection. The expected responses to the fourth cycle of RRS and the probability of selecting double-crosses from $\mathrm{C}_{3}$ that outperform those from $\mathrm{C}_{0}$ showed that the decreases in the genetic variances were not great enough to limit the continued improvement of the populations as well as the use of the improved populations as sources of inbred lines to develop commercial hybrids. However, if the magnitudes of the genetic variances continue to decrease, new sources of improved germplasm should be incorporated into both populations to allow the continued improvement of the interpopulation by RRS.
\end{abstract}

Key words: maize, responses to selection, genetic variances, genetic correlations.

Received: July 2, 2004; Accepted: March 23, 2005.

\section{Introduction}

Reciprocal recurrent selection (RRS) is a cyclical breeding procedure designed to improve the cross of two populations from different heterotic groups by using both general and specific combining ability. In this procedure, genotypes from two populations are evaluated in reciprocal crosses and the best genotypes of each population are selected and recombined to give rise to improved population crosses. Interpopulation half-sib or full-sib progenies are used as evaluation units and intrapopulation $\mathrm{S}_{1}$ progenies as recombination units (Comstock et al., 1949; Hallauer and Eberhart, 1970). Reported results from this breeding procedure have shown that RRS has been highly effective to improve the population crosses in maize (Zea mays L.) (Hallauer et al., 1988; Eyherabide and Hallauer, 1991; Souza Jr. and Pinto, 2000; Rezende and Souza Jr., 2000). Furthermore, RRS is directly related to the improvement of hybrids from inbred lines (Comstock, 1964; Souza Jr., 2001) and reported results from this procedure have shown that single-crosses developed from advanced cycles of se-

Send correspondence to Cláudio Lopes de Souza Jr. Universidade de São Paulo, Escola Superior de Agricultura "Luiz de Queiroz", Departamento de Genética, Caixa Postal 83, 13.400-970 Piracicaba, SP, Brazil. E-mail: clsouza@esalq.usp.br. lection presented superior performances, as higher yields and lower lodgings, than those from original non-improved populations (Moll et al., 1977; Russell, 1985; Betrán and Hallauer, 1996).

In RRS breeding programs selection intensity is usually high (10\% to $20 \%)$, and $\mathrm{S}_{1}$ progenies are used as recombination units which have low effective population size; i.e., $\mathrm{Ne}=1$ for each $\mathrm{S}_{1}$ progeny. Then, a reduction in the population sizes will occur, and as a consequence genetic drift is expected to take place in the selected populations (Souza Jr. et al., 2000). Hence, because of the joint effects of the selection and of the genetic drift, the genetic variability of the traits being selected could be reduced after some cycles of selection and, consequently, the selection response could also be reduced to such a level that the selected populations become unfeasible as source populations for the development of commercial hybrids (Souza Jr., 1999; Souza Jr., 2001). Estimates of genetic variances for several traits, including grain yield, have not been significantly reduced in either long-term RRS programs (Stucker and Hallauer, 1992; Schnicker and Lamkey, 1993; Holthaus and Lamkey, 1995) or in short-term RRS programs where selection intensity was greater than $10 \%$ (Bernardo, 1996; Rezende and Souza Jr., 2000). However, 
molecular marker studies in the populations submitted to RRS showed that there were significant losses and/or fixation of alleles because of genetic drift effects (Labate et al., 1997; Pinto et al., 2003a; Pinto et al., 2003b), and significant genetic drift effects on the means of several traits in maize populations undergoing RRS programs have also been reported (Smith, 1983; Helms et al., 1989; Keeratinijakal and Lamkey, 1993).

Since RRS is a long-term breeding procedure, the maintenance of the genetic variability during the cycles of selection is necessary to ensure adequate magnitudes of selection responses for several cycles. Hence, the responses to selection and the magnitudes of the genetic variances of the traits under selection should be evaluated periodically. The objectives of this paper were to report the responses to selection, the changes in genetic variances, and in the genetic correlations for several traits after three cycles of RRS in the IG-1 and IG-2 maize populations.

\section{Material and Methods}

\section{Germplasm and selection procedures}

The IG-1 and IG-2 maize populations used in this study are early-maturing with orange flint and yellow dent kernels, respectively, and they were released by the maize breeding program of the Department of Genetics, Escola Superior de Agricultura “Luiz de Queiroz”, São Paulo University (ESALQ/USP), Piracicaba, São Paulo, Brazil. Population IG-1 was developed by crossing the populations EPB-5 and BR-105 and subsequently this cross was crossed to an elite single-cross HS-1, i.e. [EPB-5 x BR-105] $\mathrm{x}$ HS-1. Population IG-2 was developed by crossing the populations EPB-4 and BR-106 and subsequently this cross was crossed to an elite single-cross HS-2, i.e. [EPB-4 $\mathrm{x}$ BR-106] x HS-2. Thus, the germplasm of IG-1 and IG-2 populations comprised $50 \%$ of elite single-crosses plus $25 \%$ of each one of two populations. Single-crosses HS-1 and HS-2, the parents of the double-cross BR-201, and BR-105 and BR-106 populations were released by EMBRAPA/Milho e Sorgo, while EPB-4 and EPB-5 populations were released by the Department of Genetics, ESALQ/USP. All materials used to develop the IG-1 and IG-2 populations were from tropical germplasm (Rezende and Souza Jr., 2000; Souza Jr. and Pinto, 2000).

In the agricultural season of 1989/1990 a RRS program with the IG-1 and IG-2 maize populations was initiated using interpopulation half-sib progenies as evaluation units and $\mathrm{S}_{1}$ progenies as recombination units. Twothousand plants from each population were grown in contiguous blocks in a stand of 62,500 plants $\mathrm{ha}^{-1}$ at the Experimental Station of the Department of Genetics in Piracicaba, SP, Brazil $\left(22^{\circ} 42^{\prime} \mathrm{S}, 47^{\circ} 38^{\prime} \mathrm{W}\right)$. In both populations the lower ears were selfed and the upper ears were crossed with a pollen mixture from the opposite population. Then, from each plant an $S_{1}$ and an interpopulation half-sib progeny were obtained. The plants that gave rise to the progenies were selected for lower plant and ear heights during the pollinations and only erect plants were harvested. Twohundred pairs of progenies were obtained from each population. In the following agricultural season (1990/1991) the interpopulation half-sib progenies were evaluated at three locations near the city of Piracicaba (Experimental Stations of Caterpillar, Areão, and Department of Genetics) with two replications per location. Each set of one-hundred progenies were allocated in a $10 \times 10$ lattice design, and two commercial hybrids were also allocated at the beginning and at the end of each replication out of the lattice design as checks in each lattice. Plots were one-row $4 \mathrm{~m}$ long spaced $0.8 \mathrm{~m}$ between rows. All plots were overplanted and thinned to 20 plants per row $\left(62,500\right.$ plants ha $\left.{ }^{-1}\right)$. Data for grain yield, plant and ear heights, and stalk and root lodging were recorded. Grain yield was adjusted to $15.5 \%$ grain moisture and corrected to the average stand of the experiments. After statistical analyses the mean of the traits evaluated of each progeny was expressed as a percentage of the checks mean in each lattice, i.e., $\overline{\mathrm{Y}}_{P i} \%=\left(\overline{\mathrm{Y}}_{P i} / \overline{\mathrm{Y}}_{C h}\right) .100$, where $\overline{\mathrm{Y}}_{P i}$ and $\overline{\mathrm{Y}}_{C h}$ are the means of the ith progeny and of the checks, respectively. The two-hundred progenies of each population were then compared for selection and twenty progenies from each population were selected $(10 \%$ selection intensity) based mainly on grain yield and root and stalk lodging; interpopulation progenies with above average plant and ear heights were discarded. In the next season (1991/1992) the $S_{1}$ progenies from the plants that gave rise to the selected interpopulation half-sib progenies from each population were recombined to give rise to the IG-1 cycle 1 and IG-2 cycle 1 . Two further cycles of RRS $\left(\mathrm{C}_{2}\right.$ $1992 / 1993$ to $1994 / 1995$; and $C_{3} 1995 / 1996$ to $1997 / 1998$ ) were carried out at the same locations using the same procedures.

\section{Experimental procedures}

In the breeding nursery of the agricultural season of 1998/1999, 400 plants of each population were grown in contiguous plots to develop interpopulation full-sib progenies from cycle zero $\left(\mathrm{C}_{0}\right)$ and from cycle three $\left(\mathrm{C}_{3}\right)$ using random $\mathrm{S}_{0}$ plants. Reciprocal crosses were not made; populations IG-2 $\mathrm{C}_{0}$ and IG-2 $\mathrm{C}_{3}$ were used as females, and IG-1 $\mathrm{C}_{0}$ and IG-1 $\mathrm{C}_{3}$ as males in the crosses, and each plant were used once as male. From each cross (IG-1C $\mathrm{C}_{0} \mathrm{x} \mathrm{IG}-2 \mathrm{C}_{0}$ and IG- $\left.1 \mathrm{C}_{3} \times \mathrm{IG}-2 \mathrm{C}_{3}\right) 300$ plants were pollinated. After harvest, 200 interpopulation progenies with enough seeds for evaluation were randomly taken from each selection cycle. The 400 progenies were allocated in four 10x10 lattices experiments, with 50 progenies from $\mathrm{C}_{0}$ and 50 progenies from $\mathrm{C}_{3}$ being allocated to each lattice. The progenies were evaluated in the agricultural season of 1999/2000 at two locations (Experimental Station of Caterpillar and Experimental Station of Areão) near Piracicaba, São Paulo State, with two replications per location. Plots were one row $4.0 \mathrm{~m}$ 
long spaced $0.8 \mathrm{~m}$ between plots. Plots were overplanted and thinned to 20 plants $\operatorname{plot}^{-1}\left(62,500\right.$ plants ha $\left.{ }^{-1}\right)$. Data were recorded for grain yield $\left(\mathrm{g} \mathrm{plant}^{-1}\right)$, plant and ear heights $\left(\mathrm{cm} \mathrm{plant}^{-1}\right)$, stand (plants plot $\left.{ }^{-1}\right)$, grain moisture (\%), lodging as stalk lodging plus root lodging (plants ha ${ }^{-1}$ ), and number of ears per plot. Plant and ear heights were recorded in five competitive plants per plot, from the ground level to the collar of the flag leaf and to the uppermost ear node, respectively; and the plot means were used for analysis. Ear placement was computed per plot by the ratio mean ear height/mean plant height; prolificacy was computed per plot by the ratio number of ears per plot/stand; and lodging was transformed by $(x+0.5)^{1 / 2}$, and $\mathrm{x}$ stand for the number of lodged plants per plot. Grain yield, prolificacy, and lodging were adjusted for average stand by covariance analyses, and grain yield was also adjusted to grain moisture of $15 \%$.

\section{Statistical analyses}

Analyses of variance for each trait and covariance for pairs of traits were performed sequentially: for each experiment at each location, joint analyses across locations for each experiment and, finally, the analyses of variances were pooled across experiments and locations. The sum of squares and the sum of products of entries were partitioned into $\mathrm{C}_{0}$ progenies, $\mathrm{C}_{3}$ progenies, and the contrast $\mathrm{C}_{0} \times \mathrm{C}_{3}$; the entries $\mathrm{x}$ location sum of squares and sum of products were partitioned accordingly. Progenies and locations were considered as random effects and the contrast $C_{0} \times C_{3}$ was considered as a fixed effect. The progenies $\mathrm{x}$ location interaction mean squares were used as errors in the $F$ tests for progenies, whereas for the contrast $\mathrm{C}_{0} \mathrm{x} \mathrm{C}_{3}$ the error mean squares were used in the denominator for the $F$ tests. The pooled analyses of variance were used to estimate the components of genetic variances and covariances using the method of moments (Searle et al., 1992), i.e., the mean squares were equated to their respective expectations and the estimates of variance for each cycle of selection were computed as follows: $\hat{\sigma}_{P}^{2}=\left(M S_{P}-M S_{P L}\right) / R L$ as the variance among interpopulation full-sib progenies; $\hat{\sigma}_{P L}^{2}=\left(M S_{P L}-M S_{E}\right) / R$ as the variance of the interaction progenies vs. locations; and $\hat{\sigma}_{P h}^{2}=M S_{P} / R L$ as the phenotypic variance on a progeny-mean basis. In these expressions, $M S_{P}, M S_{P L}, M S_{E}$, refer to the mean squares of progenies, progeny by location interaction, and error; $R$ and $L$ refer to the number of replications and locations, respectively. Estimates of the heritability coefficients on a progeny-mean basis were computed as $\hat{h}^{2}=\hat{\sigma}_{P}^{2} / \hat{\sigma}_{P h}^{2}$; estimates of the expected response to truncated selection as $R_{S(12)}=i\left(\hat{\sigma}_{P}^{2} / \hat{\sigma}_{P h}^{2}\right)$ where $i$ is the standardized selection differential, and a $20 \%$ selection intensity $(i=1.4)$ were used in all instances, and the expected means for the fourth cycle $\left(\mu_{C 4}\right)$ of selection as $\mu_{C 4}=\mu_{C 3}+R_{S(12)}$, where $\mu_{C 3}$ is the mean of the third selection cycle (Falconer and Mackay, 1996). Notice that because $\hat{\sigma}_{P}^{2}$ refers to the genetic variance of interpopulation full-sib progenies, which equals the ge- netic variance of the double-cross hybrids from inbred lines (Souza Jr., 1992), the heritability coefficients, the responses to selection, and the expected means for the fourth cycle did not refer to the population cross but to the double-cross hybrids from inbred lines. Confidence intervals at the 0.95 probability level were estimated for the estimates of genetic variances and heritability coefficients following the procedures of Burdick and Graybill (1992). The genetic covariance between traits $(\mathrm{x}, \mathrm{y})$ were estimated from the covariance analyses as $C \hat{o} v=\left(M P_{P}-M P_{P L}\right) / R L$, in which $M P_{P}$ and $M P_{P L}$ refer to mean products of the progenies and of the interaction progenies by location, respectively, and the genetic correlations between traits ( $\mathrm{x}$ and $\mathrm{y}$ ) were estimated as $r_{G(x y)}=C \hat{o} v_{P(x y)} / \hat{\sigma}_{P x} \hat{\sigma}_{P y}$, where $\hat{\sigma}_{P}(x$ or $y)$ refers to the square root of the genetic variance of progenies for traits $\mathrm{x}$ and $\mathrm{y}$ (Falconer and Mackay, 1996). The probabilities of selecting double-cross hybrids (interpopulation full-sib progenies) with means higher than or lower than the mean of the $\mathrm{C}_{3}$ plus one and a half times $\left(X_{1}\right)$ and twice $\left(X_{2}\right)$ the phenotypic standard deviation of the $\mathrm{C}_{3}$ $\left(X_{1}=\bar{X}_{C 3} \pm 1.5 \sigma_{P h C 3}\right.$ and $\left.X_{2}=\bar{X}_{C 3} \pm 2 \sigma_{P h C 3}\right)$ were computed for $\mathrm{C}_{0}$ and $\mathrm{C}_{3}$ using the properties of the normal distribution as follows: the means of all traits for both selection cycles were standardized, i.e., $Z_{C i}=\left(X_{i}-\bar{X}_{C i}\right) / \sigma_{P h C i}$, where $X_{i}$ refers to $X_{1}$ or $X_{2}$, and $\bar{X}_{C i}$ and $\sigma_{P h C i}$ are the means and the standard phenotypic deviations, respectively, from $\mathrm{C}_{0}$ or $\mathrm{C}_{3}$, and then the probabilities were obtained from the normal distribution table that gives the proportion of the normal curve that lies beyond $X_{1}$ and $X_{2}$, i.e., $P\left(X \geq X_{i}\right)=P\left(Z \geq Z_{i}\right)$ or $P\left(X \leq X_{i}\right)=P\left(Z \leq Z_{i}\right)$ (Zar, 1999).

Realized responses to selection per cycle in the interpopulation were computed as $\left(\bar{X}_{C 3}-\bar{X}_{C 0}\right) / 3$ in actual units, and multiplied by 100 to express them as a percentage; $\bar{X}_{C 3}$ and $\bar{X}_{C 0}$ stand for the means of the traits evaluated at cycle three and at cycle zero, respectively. Distributions of the traits of the interpopulation full-sib progenies from both cycles of selection were tested for normality ( $W$ test), skewness and kurtosis following the procedures described by Zar (1999).

\section{Results and Discussion}

Highly significant differences $(p \leq 0.01)$ were detected in the pooled analyses of variances for locations and for interpopulation full-sib progenies, but the progeny by location interactions were not significant for all traits evaluated. Thus, genetic variation among progenies was detected, and the performances of the progenies did not differ across locations, although the difference between locations was highly significant. Highly significant differences were also detected for the $\mathrm{C}_{0}$ progenies and for the $\mathrm{C}_{3}$ progenies, and the interactions $\mathrm{C}_{0} \mathrm{x}$ location and $\mathrm{C}_{3} \mathrm{x}$ location were not significant for any trait, except for lodging from $\mathrm{C}_{0}$, indicating that there was genetic variation among progenies for both selection cycles, and that the performances of the 
progenies from both selection cycles were consistent across locations, except for lodging from $\mathrm{C}_{0}$. The contrasts $\mathrm{C}_{0} v s$. $\mathrm{C}_{3}$ were highly significant for all traits, except for lodging, indicating that there were significant changes in the means of the traits from $\mathrm{C}_{0}$ to $\mathrm{C}_{3}$. Also, the contrasts by environment interactions were highly significant for all traits, except for prolificacy, which indicated that the responses to selection differed significantly between locations. Average grain yield was $123.81 \mathrm{~g} \mathrm{plant}^{-1}$ (7.74 ton ha $\mathrm{g}^{-1}$ ), and the coefficient of experimental variation was $11.92 \%$ (Table 1 ).

The reciprocal recurrent selection was effective; i.e., the means of the traits evaluated changed according to the objectives of the breeding program. Grain yield and prolificacy increased significantly; and plant height, ear height, and ear placement decreased significantly. Although the analysis of variance did not detect significant changes, there was a high decrease in lodging. Grain yield increased $890.63 \mathrm{~kg} \mathrm{ha}^{-1}$ (14.25 $\mathrm{g}$ plant $\left.^{-1}\right)$ and prolificacy increased 4,375 ears ha-1 (0.07 ears plant $\left.{ }^{-1}\right)$ after the three cycles of selection, which correspond to $296.88 \mathrm{~kg} \mathrm{ha}^{-1}$ cy$\operatorname{cle}^{-1}\left(4.07 \%\right.$ cycle $\left.^{-1}\right)$ and $1,458.33$ ears ha $^{-1}$ cycle $^{-1}$ or 0.02 ears plant cycle $^{-1}\left(2.62 \%\right.$ cycle $\left.^{-1}\right)$, respectively. Plant height, ear height, and ear placement decreased $11.73 \mathrm{~cm}$ plant $^{-1}, 11.79 \mathrm{~cm} \mathrm{plant}^{-1}$, and 0.02 after the three cycles of selection, which correspond to $-3.91 \mathrm{~cm}^{-1 a n t^{-1}}$ cycle $^{-1}$ $\left(-1.81 \%\right.$ cycle $\left.^{-1}\right),-3.93 \mathrm{~cm} \mathrm{plant}^{-1}$ cycle $^{-1}\left(3.17 \%\right.$ cycle $\left.^{-1}\right)$, and to $-6.6610^{-3}\left(-1.17 \%\right.$ cycle $\left.^{-1}\right)$, respectively. Lodging decreased 3,131.94 plants ha $^{-1}$ after the three cycles; i.e., $-1,044$ plants ha ${ }^{-1}$ cycle $^{-1}\left(-15.06 \%\right.$ cycle $\left.^{-1}\right)$ (Table 2$)$. The response to selection for grain yield per cycle was lower than those reported by Schnicker and Lamkey (1993) $\left(6.46 \%\right.$ cycle $\left.^{-1}\right)$, Keeratinajakal and Lamkey (1993) $(6.95 \%$ cycle $\left.^{-1}\right)$, and by Souza Jr. and Pinto (2000) (7.20\% cycle $\left.^{-1}\right)$, and greater than those reported by Paterniani and
Vencovsky (1978) $\left(3.50 \%\right.$ cycle $\left.^{-1}\right)$; for lodging the response to selection was greater than those reported by Schnicker and Lamkey (1993) (-1.85\% cycle $\left.{ }^{-1}\right)$ and by Souza Jr. and Pinto (2000)(-13.50\% cycle $\left.{ }^{-1}\right)$; also, for plant and ear heights the responses to selection per cycle were greater than those reported by Schnicker and Lamkey (1993) and by Souza Jr. and Pinto (2000). Hence, the performance of the cross IG-1 x IG-2 was improved significantly after three cycles of selection, indicating that the frequency of favorable complementary alleles in the reciprocal populations increased following the cycles of selection. The means of the traits of an interpopulation correspond to the means of the traits of the interpopulation single-crosses from inbred lines randomly developed from the two populations (Souza Jr., 2001), and then one could expect that the single-crosses selected from $\mathrm{C}_{3}$ will present better performance than those ones selected from $\mathrm{C}_{0}$.

The distribution of the means of the interpopulation full-sib progenies from $\mathrm{C}_{0}$ and from $\mathrm{C}_{3}$ remained normal ( $W$ test nonsignificant), and skewness and kurtosis tests were also non-significant for all traits, except for lodging in $\mathrm{C}_{3}$. Thus, three cycles of RRS did not change the normality of the distributions of the interpopulation full-sib progenies. Similar results for grain yield, plant height, and ear height have been reported by Schnicker and Lamkey (1993) and Rezende and Souza Jr. (2000).

Estimates of interpopulation full-sib genetic variances and estimates of the heritability coefficients differed significantly $(\mathrm{p} \leq 0.05)$ from zero for both $\mathrm{C}_{0}$ and $\mathrm{C}_{3}$. The estimates of genetic variance of all traits from $\mathrm{C}_{3}$ were significantly lower than those from $\mathrm{C}_{0}$, except for ear placement that did not differ. From $\mathrm{C}_{0}$ to $\mathrm{C}_{3}$ genetic variance decreased $40.18 \%$ for grain yield, $69.70 \%$ for lodging,

Table 1 - Values and significances of the mean squares from the joint analyses of variances for several traits.

\begin{tabular}{|c|c|c|c|c|c|c|c|}
\hline \multirow[b]{2}{*}{$\mathrm{SV}^{1}$} & \multirow[b]{2}{*}{ DF } & \multicolumn{6}{|c|}{ Mean squares } \\
\hline & & $\begin{array}{l}\text { Grain yield } \\
\text { g plant }^{-1}\end{array}$ & $\begin{array}{l}\text { Lodging }^{2} \\
\text { plants ha }\end{array}$ & $\begin{array}{l}\text { Prolificacy }^{3} \\
\text { ears plant }^{-1}\end{array}$ & $\begin{array}{l}\text { Plant height } \\
\mathrm{cm} \mathrm{plant}^{-1}\end{array}$ & $\begin{array}{l}\text { Ear height } \\
\mathrm{cm}^{-1 a n t^{-1}}\end{array}$ & $\begin{array}{c}\text { Ear placement } \\
\mathrm{Eh} / \mathrm{Ph}\end{array}$ \\
\hline Locations (L)/E & 1 & $1,510.00^{* *}$ & $680.94^{* *}$ & $480.00^{* *}$ & $910.00^{* *}$ & $280.00^{* *}$ & $2,730.49^{* *}$ \\
\hline Progenies/E (P) & 396 & $716.34^{* *}$ & $48.60^{* *}$ & $207.66^{* *}$ & $406.11^{* *}$ & $310.05^{* *}$ & $25.48^{* *}$ \\
\hline P. cycle $0\left(\mathrm{C}_{0}\right)$ & 196 & $720.41^{* *}$ & $62.29^{* *}$ & $215.36^{* *}$ & $402.70^{* *}$ & $278.54^{* *}$ & $21.42^{* *}$ \\
\hline P. cycle $3\left(\mathrm{C}_{3}\right)$ & 196 & $499.65^{* *}$ & $27.72^{* *}$ & $140.64^{* *}$ & $275.85^{* *}$ & $210.56^{* *}$ & $21.91^{* *}$ \\
\hline$\left(\mathrm{P} . \mathrm{C}_{0} v s . \mathrm{P} . \mathrm{C}_{3}\right) / \mathrm{E}$ & 4 & $2,474.00^{* *}$ & $14.37^{\mathrm{ns}}$ & $641.93^{*}$ & $814.06^{*}$ & $859.05^{* *}$ & $3,436.20^{* *}$ \\
\hline$(\mathrm{P} \times \mathrm{L}) / \mathrm{E}$ & 396 & $240.07^{\mathrm{ns}}$ & $22.00^{\mathrm{ns}}$ & $95.61^{\mathrm{ns}}$ & $79.68^{\mathrm{ns}}$ & $54.61^{\mathrm{ns}}$ & $6.15^{\mathrm{ns}}$ \\
\hline P. $\mathrm{C}_{0} \times \mathrm{L}$ & 196 & $247.53^{\mathrm{ns}}$ & $24.92^{*}$ & $109.72^{\mathrm{ns}}$ & $73.64^{\mathrm{ns}}$ & $54.73^{\mathrm{ns}}$ & $5.41^{\mathrm{ns}}$ \\
\hline P. $\mathrm{C}_{3} \times \mathrm{L}$ & 196 & $216.78^{\mathrm{ns}}$ & $16.40^{\mathrm{ns}}$ & $80.48^{\mathrm{ns}}$ & $79.69^{\mathrm{ns}}$ & $45.88^{\mathrm{ns}}$ & $6.09^{\mathrm{ns}}$ \\
\hline$\left(\mathrm{P} . \mathrm{C}_{0} v s . \mathrm{P} . \mathrm{C}_{3}\right) \times \mathrm{L}$ & 4 & $1,015.63^{* *}$ & $153.35^{* *}$ & $145.70^{\mathrm{ns}}$ & $375.37^{* *}$ & $476.64^{* *}$ & $45.25^{* *}$ \\
\hline Error & 648 & 217.74 & 21.54 & 98.25 & 71.14 & 47.57 & 5.53 \\
\hline Means & & 123.81 & $3,938.63$ & 0.93 & 209.47 & 117.80 & 0.56 \\
\hline $\mathrm{CV} \%$ & & 11.92 & 37.27 & 10.66 & 4.02 & 5.85 & 4.18 \\
\hline
\end{tabular}

${ }^{1}$ E refers to experiments. ${ }^{2,3}$ Means squares multiplied by $10^{-5}$ and by $10^{4}$, respectively. ${ }^{\mathrm{ns}},{ }^{*},{ }^{* *}$ non-significant, $\mathrm{p} \leq 0.05$ and $\mathrm{p} \leq 0.01$, respectively. 
Table 2 - Mean values across environments of the interpopulation (IG-1 x IG-2) from original (Cycle 0) and after three cycles (Cycle 3) of reciprocal recurrent selection, and the responses to selection per cycle in actual units and in percentage for several traits.

\begin{tabular}{|c|c|c|c|c|}
\hline \multirow[t]{2}{*}{ Traits } & \multicolumn{2}{|c|}{ IG-1 x IG-2 } & \multirow{2}{*}{$\begin{array}{l}\text { Response } \\
\text { per cycle }\end{array}$} & \multirow{2}{*}{$\begin{array}{c}\text { Response } \\
\text { per cycle }(\%)\end{array}$} \\
\hline & Cycle 0 & Cycle 3 & & \\
\hline Grain yield (g plant ${ }^{-1}$ ) & $116.68 \pm 3.93$ & $130.93 \pm 3.68$ & 4.75 & 4.07 \\
\hline Lodging (plants ha ${ }^{-1}$ ) & $6,930.55 \pm 1,451.21$ & $3,798.61 \pm 937.75$ & $-1,044.00$ & -15.06 \\
\hline Prolificacy (ears plant ${ }^{-1}$ ) & $0.89 \pm 0.02$ & $0.96 \pm 0.02$ & 0.02 & 2.62 \\
\hline Plant height $\left(\mathrm{cm}\right.$ plant $\left.^{-1}\right)$ & $215.33 \pm 2.14$ & $203.60 \pm 2.23$ & -3.91 & -1.81 \\
\hline Ear height $\left(\mathrm{cm}\right.$ plant $\left.{ }^{-1}\right)$ & $123.69 \pm 1.85$ & $111.90 \pm 1.69$ & -3.93 & -3.17 \\
\hline Ear placement $(\mathrm{Eh} / \mathrm{Ph})$ & $0.57 \pm 0.006$ & $0.55 \pm 0.006$ & -0.006 & -1.17 \\
\hline
\end{tabular}

$43.08 \%$ for prolificacy, $40.38 \%$ for plant height, and $26.41 \%$ for ear height, under RRS (Table 3). These results differ from those reported either for long-term (Stucker and Hallauer, 1992; Schnicker and Lamkey, 1993; Holthaus and Lamkey, 1995) or for short-term high-intensity selection RRS breeding programs (Bernardo, 1996; Rezende and Souza Jr., 2000) in which the interpopulation genetic variances for several traits remained unchanged after the cycles of RRS. The number of selected progenies per cycle $(20)$ and the type of progeny used for recombination $\left(\mathrm{S}_{1}\right)$ resulted in a lower effective population number per cycle $(\mathrm{Ne}=20$ per cycle $)$ in the populations, and after three selection cycles fixation and/or loss of alleles are expected to occur because of the genetic drift effects caused by the lower effective sizes of the populations under selection (Labate $e t$ al., 1999; Pinto et al., 2003a; Pinto et al., 2003b). Thus, because of the joint effects of selection and of genetic drift one could expect that the genetic variances will reduce throughout the cycles of selection as was reported in our study.

Estimates of the heritability coefficients differed significantly $(\mathrm{p} \leq 0.05)$ from zero for all traits for both $\mathrm{C}_{0}$ and $\mathrm{C}_{3}$ for all traits. Differently from the genetic variances, the heritability coefficients remained unchanged $(p \leq 0.05)$ from $\mathrm{C}_{0}$ to $\mathrm{C}_{3}$ for all traits, except for plant height and lodging which decreased $12.97 \%$ and $31.93 \%$, respectively. The decreases in the magnitudes of the phenotypic variances from $\mathrm{C}_{0}$ to $\mathrm{C}_{3}$ were similar to that of the genetic variances, and as the heritability coefficient is a ratio of these parameters, the estimates of the heritability coefficients remained unchanged from $\mathrm{C}_{0}$ to $\mathrm{C}_{3}$ for all traits, except for plant height and lodging where the decreases in the genetic variances were greater than the decreases in the phenotypic variances leading to the reductions in the heritability coefficients. The expected responses to truncated selection for the fourth cycle of RRS $\left(\mathrm{C}_{4}\right)$ for each trait was $6.76 \%$ for grain yield, $-13.64 \%$ for lodging, and $3.67 \%$ for prolificacy,

Table 3 - Estimates of genetic $\left(\hat{\sigma}_{P}^{2}\right)$ and phenotypic $\left(\hat{\sigma}_{P h_{C}}^{2}\right)$ variances, and heritability coefficients $\left(h_{\bar{X}}^{2} \%\right)$ for cycles zero $\left(\mathrm{C}_{0}\right)$ and three $\left(\mathrm{C}_{3}\right)$, and expected responses to selection $\left(R S_{H(12)} \%\right)$ and expected means $\left(\mu M_{H(12)_{C 4}}\right)$ for the fourth cycle of selection for several traits.

\begin{tabular}{|c|c|c|c|c|c|c|}
\hline \multirow[t]{2}{*}{ Parameters } & \multicolumn{6}{|c|}{ Traits $^{1}$} \\
\hline & $\begin{array}{l}\text { Grain yield } \\
\text { g plant }^{-1}\end{array}$ & $\begin{array}{l}\text { Lodging }^{3} \\
\text { plants ha }^{-1}\end{array}$ & $\begin{array}{l}\text { Prolificacy }{ }^{2} \\
\text { ears plant }^{-1}\end{array}$ & $\begin{array}{l}\text { Plant height } \\
\text { cm plant }^{-1}\end{array}$ & $\begin{array}{l}\text { Ear height } \\
\mathrm{cm} \text { plant }^{-1}\end{array}$ & $\begin{array}{c}\text { Ear placement }{ }^{2} \\
\mathrm{Eh} / \mathrm{Ph}\end{array}$ \\
\hline$\hat{\sigma}_{P_{C 0}}^{2}$ & $\begin{array}{c}118.22 \\
{[88.54 ; 168.66]}\end{array}$ & $\begin{array}{c}9.34 \\
{[6.81 ; 14.03]}\end{array}$ & $\begin{array}{c}26.41 \\
{[17.76 ; 44.73]}\end{array}$ & $\begin{array}{c}82.26 \\
{[65.53 ; 107.59]}\end{array}$ & $\begin{array}{c}55.95 \\
{[44.45 ; 73.74]}\end{array}$ & $\begin{array}{c}4.00 \\
{[3.13 ; 5.42]}\end{array}$ \\
\hline$\hat{\sigma}_{P_{C 3}}^{2}$ & $\begin{array}{c}70.71 \\
{[50.65 ; 110.06]}\end{array}$ & $\begin{array}{c}2.83 \\
{[1.74 ; 5.52]}\end{array}$ & $\begin{array}{c}15.03 \\
{[9.41 ; 27.88]}\end{array}$ & $\begin{array}{c}49.04 \\
{[37.60 ; 67.46]}\end{array}$ & $\begin{array}{c}41.17 \\
{[32.39 ; 54.57]}\end{array}$ & $\begin{array}{c}3.95 \\
{[3.05 ; 5.43]}\end{array}$ \\
\hline$\hat{\sigma}_{P h_{C 0}}^{2}$ & 180.10 & 15.57 & 53.84 & 100.67 & 69.63 & 5.35 \\
\hline$\hat{\sigma}_{P h_{C 3}}^{2}$ & 124.91 & 6.93 & 35.15 & 68.96 & 52.64 & 5.47 \\
\hline$h_{\bar{X}_{C 0}}^{2}$ & $\begin{array}{c}65.63 \\
{[54.50 ; 74.05]}\end{array}$ & $\begin{array}{c}59.98 \\
{[47.01 ; 69.78]}\end{array}$ & $\begin{array}{c}49.05 \\
{[32.53 ; 61.52]}\end{array}$ & $\begin{array}{c}81.71 \\
{[75.78 ; 86.19]}\end{array}$ & $\begin{array}{c}80.35 \\
{[73.97 ; 85.16]}\end{array}$ & $\begin{array}{c}74.74 \\
{[66.55 ; 80.92]}\end{array}$ \\
\hline$h_{\bar{X}_{C 3}}^{2}$ & $\begin{array}{c}56.61 \\
{[42.54 ; 67.23]}\end{array}$ & $\begin{array}{c}40.83 \\
{[21.65 ; 55.32]}\end{array}$ & $\begin{array}{c}42.77 \\
{[24.22 ; 56.78]}\end{array}$ & $\begin{array}{c}71.11 \\
{[61.74 ; 78.18]}\end{array}$ & $\begin{array}{c}78.20 \\
{[71.14 ; 83.54]}\end{array}$ & $\begin{array}{c}72.19 \\
{[63.17 ; 79.00]}\end{array}$ \\
\hline$R S_{H(12)} \%$ & 6.76 & -13.64 & 3.67 & -4.06 & -7.09 & -4.30 \\
\hline$\mu M_{H(12)_{C 4}}$ & 139.79 & $3,011.00$ & 1.00 & 195.33 & 103.96 & 0.52 \\
\hline
\end{tabular}

${ }^{1}$ Confidence intervals at the $90 \%$ probability level between brackets. ${ }^{2,3}$ Estimates multiplied by $10^{4}$ and by $10^{-5}$, respectively. 
while plant stature will be reduced in $-7.09 \%,-4.06 \%$, and $-4.30 \%$ for plant height, ear height, and ear placement, respectively. Thus, the interpopulation (IG-1 x IG-2) in the fourth cycle of reciprocal recurrent selection $\left(\mathrm{C}_{4}\right)$ should have the following means: $8,737.16 \mathrm{~kg} \mathrm{ha}^{-1}$ (139.79 $\mathrm{g}$ plant $^{-1}$ ) for yield, 3,011 plants ha ${ }^{-1}$ lodged, 1 ear plant ${ }^{-1}$, $195.33 \mathrm{~cm}$ plant $^{-1}$ as plant height, $103.96 \mathrm{~cm}$ plant $^{-1}$ as ear height, and an ear placement of 0.52 (Table 3). Although truncated selection was not practiced in breeding programs, these results showed that the magnitudes of the reduction in the genetic variability of the traits evaluated were not great enough to reduce significantly the responses to the following RRS cycle. However, as there were high decreases in the genetic variances for all traits, they have to be monitored in the following selection cycles to circumvent the decrease in the responses to selection.

The genetic variance of interpopulation full-sib progenies are the same as for double-cross hybrids from inbred lines randomly developed from two populations (Souza Jr., 1992). To assess the effects of RRS on the development of double-crosses, the ratios between the probabilities of the development of double-crosses with performances higher than or lower than the mean of $\mathrm{C}_{3}$ cycle \pm one and a half times $\left(\Delta_{1}=P_{1 C 3} / P_{1 C 0}\right)$ and twice $\left(\Delta_{2}=P_{2 C 3} / P_{2 C 0}\right)$ the phenotypic standard deviation of the $\mathrm{C}_{3}$ cycle were computed. The results showed that, for grain yield, the probability of selecting double-crosses from $\mathrm{C}_{3}$ higher than $\mathrm{C}_{3}$ mean plus one and a half times and twice the phenotypic standard deviation of $\mathrm{C}_{3}$ were 6.42 and 6.70 times, respectively, higher than those selected from $\mathrm{C}_{0}$. For the other traits these ratios were 4.67 and 4.85, 8.35 and 9.50, 19.64 and 27.50, and 7.10 and 17.53 , for prolificacy, plant height, ear height, and ear placement, respectively. These results showed that the probability of developing outstanding double-crosses from $\mathrm{C}_{3}$ is higher than from $\mathrm{C}_{0}$. For instance, from 1,000 double-crosses (DC) developed from each cycle the expected number of double-crosses with grain yield higher than the $\mathrm{C}_{3}$ mean plus twice the phenotypic standard deviation is only three for the $\mathrm{C}_{0}$ cycle but 23 from the $\mathrm{C}_{3}$ cycle. As several traits should be selected simultaneously, the frequency of double-crosses with all traits beyond these limits will be very low in the $\mathrm{C}_{0}$, and then it is unlikely that the three predicted higher-yielding DC from $\mathrm{C}_{0}$ would be selected. Thus, RRS in IG-1 and IG-2 populations was also effective in significantly enhancing the probability of selecting outstanding double-crosses. Although there were significant reductions in the genetic variances of the traits evaluated, these reductions were not great enough to reduce the probability of selecting superior genotypes from $\mathrm{C}_{3}$, and then the IG-1 and IG-2 populations will be better sources of hybrids from inbred lines at $\mathrm{C}_{3}$ than they would be at $\mathrm{C}_{0}$ (Table 4 ).

Information on the magnitudes and signs of the genetic correlations between traits are important because several traits are selected simultaneously in maize breeding programs, and undesirable correlated responses to selection
Table 4 - Probabilities (\%) of double-crosses superior than the mean of cycle three plus one and half times $\left(P_{1}\right)$ and plus twice $\left(P_{2}\right)$ the phenotypic standard deviation for the original $\left(\mathrm{C}_{0}\right)$ and after three cycles $\left(\mathrm{C}_{3}\right)$ of reciprocal recurrent selection, and the ratios $\Delta=\left(P_{C 3} / P_{C 0}\right)$.

\begin{tabular}{lccccccc}
\hline \multirow{2}{*}{ Traits } & \multicolumn{3}{c}{$P_{1}$} & & \multicolumn{3}{c}{$P_{2}$} \\
\cline { 2 - 4 } \cline { 6 - 8 } & $\mathrm{C}_{0}$ & $\mathrm{C}_{3}$ & $\Delta_{1}$ & & $\mathrm{C}_{0}$ & $\mathrm{C}_{3}$ & $\Delta_{2}$ \\
\hline Grain yield & 1.04 & 6.68 & 6.42 & & 0.34 & 2.28 & 6.70 \\
Prolificacy & 1.43 & 6.68 & 4.67 & & 0.47 & 2.28 & 4.85 \\
Plant height & 0.80 & 6.68 & 8.35 & & 0.24 & 2.28 & 9.50 \\
Ear height & 0.34 & 6.68 & 19.64 & & 0.08 & 2.28 & 27.50 \\
Ear placement & 0.94 & 6.68 & 7.10 & & 0.13 & 2.28 & 17.53 \\
\hline
\end{tabular}

have to be avoided. Then, as for the genetic variances, the changes in the genetic correlations might be monitored during the selection cycles. There were reductions in the genetic correlations between grain yield and the other traits, except for grain yield $v s$. plant height, from $\mathrm{C}_{0}$ to $\mathrm{C}_{3}$ cycles. The genetic correlation between grain yield and prolificacy in the $\mathrm{C}_{3}$ cycle remained high ( 0.81 in $\mathrm{C}_{0}$ and 0.60 in $\mathrm{C}_{3}$ ), and it is expected that the selection for prolificacy that is practiced for the production of progenies will continue to provide additional gains for grain yield. However, selection for increase prolificacy will increase plant and ear heights because these three traits are positively correlated, and then, selection to reduce plant and ear heights might continue to be done, mainly during the development of the progenies. The genetic correlations involving lodging and the other traits in both the $\mathrm{C}_{0}$ and $\mathrm{C}_{3}$ cycles were too low to be of significance in the breeding program; the correlation between plant and ear height remained unchanged, as well as ear placement with plant and ear heights. Thus, RRS did not affect the genetic correlations consistently, i.e., some correlations increased, some decreased and some remain unchanged (Table 5). Similar results, i.e., inconsistent changes in the genetic correlations between several traits due to the joint effects of selection and genetic drift have previously been reported (Schnicker and Lamkey, 1993; Rezende and Souza Jr., 2000).

The overall results showed that RRS in IG-1 and IG-2 maize populations was highly effective to improve the means of the traits under selection in the interpopulation. Furthermore, the results also suggested that the procedure was highly effective to improve the populations as sources of inbred lines to develop commercial hybrids. The changes in the genetic correlations were not great enough to require alterations in the breeding program. However, the reductions in the interpopulation genetic variances for almost all traits are of concern and should be monitored during the following cycles of selection. If the magnitudes of the genetic variances continue to decrease, new sources of improved germplasm as elite inbred lines, single-crosses, or populations should be incorporated into both populations to increase the genetic variances of all traits to allow the con- 
Table 5 - Estimates of the genetic correlations between traits for original $\left(\mathrm{C}_{0}\right)$ and after three cycles $\left(\mathrm{C}_{3}\right)$ of reciprocal recurrent selection.

\begin{tabular}{|c|c|c|c|c|c|c|}
\hline Traits & Cycles & Plant height & Ear height & Ear placement & Prolificacy & Lodging \\
\hline \multirow[t]{2}{*}{ Grain yield } & $\mathrm{C}_{0}$ & 0.44 & 0.52 & 0.36 & 0.81 & 0.04 \\
\hline & $\mathrm{C}_{3}$ & 0.42 & 0.26 & 0.02 & 0.60 & -0.21 \\
\hline \multirow[t]{2}{*}{ Plant height } & $\mathrm{C}_{0}$ & - & 0.82 & 0.22 & 0.56 & 0.27 \\
\hline & $\mathrm{C}_{3}$ & - & 0.81 & 0.33 & 0.47 & 0.21 \\
\hline \multirow[t]{2}{*}{ Ear height } & $\mathrm{C}_{0}$ & - & - & 0.73 & 0.65 & 0.34 \\
\hline & $\mathrm{C}_{3}$ & - & - & 0.82 & 0.36 & 0.33 \\
\hline \multirow[t]{2}{*}{ Ear Placement } & $\mathrm{C}_{0}$ & - & - & - & 0.44 & 0.26 \\
\hline & $\mathrm{C}_{3}$ & - & - & - & 0.12 & 0.31 \\
\hline \multirow[t]{2}{*}{ Prolificacy } & $\mathrm{C}_{0}$ & - & - & - & - & 0.02 \\
\hline & $\mathrm{C}_{3}$ & - & - & - & - & -0.06 \\
\hline
\end{tabular}

tinued improvement of this interpopulation by reciprocal recurrent selection.

\section{Acknowledgements}

The authors are grateful to A.S. Oliveira, C.R. Segatelli, and A. Silva for technical support with field plot management, and to Dr. L.A. Carlini-Garcia for reviewing the manuscript. This research was financially supported by Conselho Nacional de Desenvolvimento Científico e Tecnológico (CNPq), Departamento de Genética, ESALQ, USP, and Coordenação de Aperfeiçoamento de Pessoal de Nível Superior (CAPES/PROAP). C.L. Souza Jr is recipient of a research fellowship from CNPq; M.F. Santos and A.M. Aguiar received fellowships from CNPq and CAPES, respectively.

\section{References}

Bernardo R (1996) Testcross selection prior to further inbreeding in maize: Mean performance and realized genetic variance. Crop Science 36:867-871.

Betrán FJ and Hallauer AR (1996) Hybrid improvement after reciprocal recurrent selection in BSSS and BSCB1 maize populations. Maydica 41:25-33.

Burdick RK and Graybill FA (1992) Confidence Intervals on Variance Components. M. Dekker, New York, 211 pp.

Comstock RE, Robinson HF and Harvey PH (1949) A breeding procedure designed to make maximum use of both general and specific combining ability. Journal of American Society of Agronomy 41:360-367.

Comstock RE (1964) Selection procedures in corn improvement. Proceedings of the Annual Corn \& Sorghum Industry Research Conference 19:87-94.

Eyherabide GH and Hallauer AR (1991) Reciprocal full-sib recurrent selection in maize. I. Direct and correlated responses. Crop Science 31:952-959.

Falconer DS and Mackay TFC (1996) Introduction to Quantitative Genetics. Longman Group Ltd., London, 464 pp.

Hallauer AR and Eberhart SA (1970) Reciprocal full-sib selection. Crop Science 10:315-316.

Hallauer AR, Russell WA and Lamkey KR (1988) Corn breding. In: Sprague GF and Dudley JW (eds) Corn and Corn Im- provement. American Society of Agronomy, Madison, pp 463-564.

Helms TC, Hallauer AR and Smith OS (1989) Genetic drift and selection evaluated from recurrent selection programs in maize. Crop Science 29:602-607.

Holthaus JF and Lamkey KR (1995) Population means and genetic variances in selected and unselected Iowa Stiff Stalk maize populations. Crop Science 35:1581-1589.

Keeratinijakal V and Lamkey KR (1993) Genetic effects associated with reciprocal recurrent selection in BSSS and BSCB1 maize populations. Crop Science 33:78-82.

Labate JA, Lamkey KR and Woodman WL (1997) Molecular genetic diversity after reciprocal recurrent selection in BSSS and BSCB1 maize populations. Crop Science 37:416-423.

Moll RH, Bari A and Stuber CW (1977) Frequency distribution of maize yield before and after reciprocal recurrent selection. Crop Science 17:794-796.

Paterniani E and Vencovsky R (1978) Reciprocal recurrent selection based on half-sib progenies and prolific plants in maize. Maydica 23:209-219.

Pinto LR, Vieira MLC, Souza Jr. CL and Souza AP (2003a) Genetic-diversity assessed by microsatellites in tropical populations submitted to a high-intensity reciprocal recurrent selection. Euphytica 134:277-286.

Pinto LR, Vieira MLC, Souza Jr. CL and Souza AP (2003b) Reciprocal recurrent selection effects on the genetic structure of tropical maize populations assessed at microsatellite loci. Genetics and Molecular Biology 26:355-364.

Rezende GSP and Souza Jr. CL (2000) A reciprocal recurrent selection procedure outlined to integrate hybrid breeding programs in maize. Journal of Genetics \& Breeding 54:57-66.

Russell WA (1985) Comparison of the hybrid performance of maize lines developed from the original and improved cycles of BSSS. Maydica 30:407-419.

Schnicker BJ and Lamkey KR (1993) Interpopulation genetic variance after reciprocal recurrent selection in BSSS and BSCB1 maize populations. Crop Science 33:90-95.

Searle SR, Casella G and MacCullock (1992) Variance Components. John Wiley \& Sons, New York, 501 pp.

Smith OS (1983) Evaluation of recurrent selection in BSSS, BSCB1 and BS13 maize populations. Crop Science 23:3540. 
Souza Jr. CL (1992) Interpopulation genetic variances and hybrid breeding programs. Brazilian Journal of Genetics 15:643656.

Souza Jr. CL (1999) Recurrent selection and heterosis. In: Coors JG and Pandey S (eds) The Genetics and Exploitation of Heterosis in Crops. American Society of Agronomy Inc., Madison, pp 247-255.

Souza Jr. CL and Pinto RMC (2000) Responses to a short-term reciprocal recurrent selection procedure in maize. Maydica 45:21-28
Souza Jr. CL, Geraldi IO and R Vencovsky (2000) Response to recurrent selection under small effective population size. Genetics and Molecular Biology 23:841-846.

Souza Jr. CL (2001) Melhoramento de espécies alógamas. In: Nass L, Valois ACC, Melo IS and Valadares-Inglis MC (eds) Recursos Genéticos \& Melhoramento. Fundação MT, Rondonópolis, pp 159-199.

Stucker DS and Hallauer AR (1992) Genetic variability as affected by selection in Iowa stiff stalk synthetic maize. Journal of Heredity 83:410-418.

Zar JH (1999) Biostatistical analysis. Prentice Hall, Upper Saddle River, 663 pp.

Editor: Fábio de Melo Sene 